\title{
THE GROSS AND HISTOLOGIC FINDINGS IN DEMENTIA PARETICA.*
}

By N. S. YAWGER, M. D.,

Assistant Physician in the Dispensary for Nervous Diseases in the Hospital of the University of Pennsylvania.

The structural changes found in dementia paretica are here considered under the headings of the skull, dura, pia-arachnoid, intra-cranial vessels and spaces, cerebrum, cranial nerves, basal ganglia, pons, cerebellum, medulla, spinal cord, cerebrospinal fluid, peripheral nerves, some adventitious substances, and changes in other parts of the body.

Generally speaking, the findings are those observed in advanced cases, though whenever possible the conditions met with earlier in the disease have been noted. Obviously, some observations, as those from studies of the blood and cerebrospinal fluid, must be made for the most part during life. Probably none of the findings in dementia paretica are pathognomonic, therefore, mention is often made of other diseases presenting similar changes. In all, eleven brains were studied, and the tissue was taken as nearly as possible from corresponding areas.

A number of investigators have endeavored to determine an organismal cause for this disease. The most extensive studies in this direction have been made by Ford Robertson in collaboration with others ( $I$ ) ; these observers stated that a diphtheroid bacillus was the cause of dementia paretica and they described two types of the organism which were called Bacillus paralyticans brevis and Bacillus paralyticans longus. Others (2), in refutation of these observations, have found diphtheroid organisms in different forms of insanity and also in the sane.

Roughly estimated, only about I or 2 per cent of syphilitics eventually develop the disease. Since syphilis has almost always preceded dementia paretica, the question is often asked, why is

* From the laboratory of neuro-pathology of the University of Pennsylvania, and the Philadelphia Hospital for the Insane. 
not syphilitic infection more frequently followed by this psychosis? One theory in answer to this is that of Hirschl, who somewhere advanced the view that dementia paretica may develop only in those cases whose near ancestors have been free from syphilitic poisoning and, therefore, may have escaped a partial immunity which otherwise might have been transmitted, had there been a luetic ancestry.

The Skull.-The changes here are limited to the calvarium, and the variations observed are in weight, thickness and texture. The weight is practically always increased; this is due to an actual thickening and also to an invasion of the diploe by the compact bony substance. Though this augmentation is most common in dementia paretica, it may likewise be present in epilepsy and paralysis. The increase may be confined to the frontal region or to the occipital region, but more rarely it is diffuse, and occasionally, there is a greater increase on one side. In texture a condensation is shown, which is due to invasion of the diploë by the compact tissue, and this very common condition is spoken of as cranio-sclerosis. To account for the changes in the calvarium, two theories have been advanced; one regarding them as inflammatory in character, and the other considering them due to nutritional disturbances.

The Dura.-On removing the calvarium the dura is often found to be decidedly adherent, but less commonly so than in senile dementia. The tissue is somewhat thickened and vascular, the vessels are tortuous and knotty, the inner surface of the membrane is silvery in appearance and is often marked by fine granulations and rusty stainings; the granulations are most numerous over the sphenoid bone and on the upper surface of the tentorium cerebelli. If death has occurred during a convulsive attack, the membrane will often show considerable congestion. The veins are much enlarged, particularly in the galloping form (3). Owing to an abundant proliferation of the cells in the neighborhood of the vessels (4), an occasional looseness of the dura is observed. Bony growths, either as spiculæ or seed-like in form, are at times met with; their presence seems to have little significance since they are almost as common in the sane; they are usually found in the falx. Adhesions are occasionally observed, however; these are present normally in the area adjacent to the superior longi- 
tudinal sinus. The subdural space is occupied by an increased amount of clear or cloudy cerebrospinal fluid. A subdural false membrane is sometimes present and this is more frequent in dementia paretica than in any other psychosis; the most common sites of this membrane are the sides of the vault and in the middle fossa at the base; it may occur on one side or on both; about its production considerable controversial literature exists. This formation has been studied most extensively perhaps by Ford Robertson (5), who recognizes two types depending upon their origin-one, as the direct outcome of a morbid process in the dura itself, and the other, as the result of hemorrhage into the subdural space, which has taken place independently of any morbid condition within the dura. Within the subdural space, the so-called meningeal hemorrhage may have occurred, and it may be in the form of a thin film of blood, or a thick coagulum; sometimes it has undergone organization and perhaps may show cystlike formations. It is worthy of note that these hemorrhages now are said to be less common since falls do not occur so frequently, because of the more careful supervision of the insane. Microscopically, the more important changes to be noted are an increase in fibrous tissue together with the changes in the endothelial cells, and these are both productive and degenerative in character. Granulations are formed and there are at times aggregations in the perivascular channels which may be mistaken for round-cell infiltration. Other cellular changes are vacuolization and fatty and hyaline degeneration. Minute hemorrhages occur within the membrane and many new capillaries are formed. Hyaline areas may be seen as may other substances whose positive chemical nature has not yet been determined.

The Pia-arachnoid.-Conditions affecting this membrane are at once seen to be serious when it is recalled that through the meshes of the pia flows all of the return blood and lymph of the cerebral tissue, and a marked retardation of this flow results in atrophy of the brain substance. On exposure this membrane may float up from an excessive accumulation of fluid underneath. Cysts are frequently seen and small hemorrhages often may be observed. A more or less widespread cloudiness of the tissue is present; to a lesser extent this is common in advanced life, and it is always present in chronic alcoholic insanity and in senile dementia; how- 
ever, this cloudiness is more extensive in dementia paretica than in any other psychosis. In cases of more than a year or so standing there are usually present variously sized dilated and congested vessels which lie in a thickened, tough, milky-colored, or opaque membrane, and these appearances are most marked over the sulci and between the convolutions, they are likewise much more apparent over the convex surface of the brain except in the occipital region, also over the inner surface, but less noticeably so over the basalar area; in places, the convolutions may be almost indiscernable. Occasionally, the changes in the soft membranes are particularly pronounced in the occipital region, but this is usually observed in those cases which begin as tabes. The Pacchionian bodies not infrequently show noticeable enlargement and in their neighborhood the membrane is particularly apt to be thickened. On removal of the membrane just after death, a blood-stained turbulent fluid oozes out. The superficial and deep surface is everywhere injected and even the cortex shows this condition. At times the pia-arachnoid is noticeably adherent to the cortex, and when stripped off, small parts of the brain substance are found attached to it. According to Mott (6), if the membrane is removed before rigor mortis sets in, it may be taken off with ease and without leaving erosions on the cortex. If a normal brain is allowed to undergo post-mortem change, there will be softening of the cortex and particles will adhere to the membrane when it is removed, therefore, these adhesions do not have the pathologic significance that has at times been bestowed upon them.

Microscopically, we find the arachnoid space lessened and in some areas obliterated. There is an increase of the tissue of the trabecular framework, a cell infiltration, to which is probably added proliferation of the endothelial cells; these little round cells have a relatively large nucleus surrounded by a small area of protoplasm; in many instances they are exceedingly numerous, packed within the irregular channels of the membrane, and they are also conspicuous about the arteries and veins, ofttimes forming a sheath about them. In cases of long standing this appearance is partly lost through disintegration and absorption. Three varieties of cells are conspicuous in this tissue; these are plasma cells, mast cells, and lymphocytes. Trypanosomiasis also gives a widespread lymphocyte and plasma cell meningeal infiltration. 
Cell disintegration is often observed; it may be pigmentary or hyaline in character; small osteoid plates are at times met with; granules of hematoidin may be seen, and granular débris, partly the result of disintegration of red blood cells and also due to breaking down of leucocytes and endothelial cells, may be observed.

The Intracranial Vessels and Spaces. -That the small vessels of the pia-arachnoid consist only of arterioles and venules, without capillaries, is the contention of Ford Robertson (7). As the disease develops, the blood-vessels become more numerous. One of the earliest changes observed is the appearance of round cells in the connective tissue sheaths of the arteries and veins; later, the entire adventitia may be invaded and even distended by these elements, the vessels are often completely ensheathed. One of the most striking features of the microscopic appearance of the cortex is the great number of small cells about the arteries, capillaries and veins; among these are to be found plasma cells which are always present in dementia paretica; the belief appears to be growing that many of these perivascular cells are plasma cells; however, just what a plasma cell includes, is a mooted question. There seem to be many atypical forms, others are not mature, and often they are undergoing deterioration; it may be for these reasons that so much difference of opinion exists. They seem to have been first described by Unna, who demonstrated their presence in the skin, and who considered them to have a local origin; he believed they were hypertrophic connective tissue cells. Marscholko regarded them as emigrated and transformed lymphocytes. They may often be seen to ensheath the vessels, around which it has been said "they cluster densely, like plant-lice upon a young shoot." Often they are found in the dilated adventitial lymphspaces of the vessels of the cortical and subcortical tissue; they occur over the whole cortex, in the central ganglia, and in the cerebelluis, Plasma cells have also been described as occurring within tie cerebral tissue ; the possibility of this being an error is pointed out by Evenson (8), when he says, " they may belong to a capillary, whose wall has not been included in the section, or which has not been stained for some cause or other." As commonly seen, the cell is large, is more or less rounded, angular, or slightly irregular in outline, contains finely granuled protoplasm 
surrounding a usually more or less eccentrically placed wheellike nucleus, just beyond which may be seen a clear area or sort of halo; sometimes a faintly stained nucleolus may be observed. The cells stain well with both theonin and toluidin blue, and, according to Unna, are often present where there is irritation of the connective tissue cells, especially in the immediate vicinity of the blood-vessels in chronic inflammations. Their function seems to be to aid in vascularization and cicatrization. Plasma cells frequently show degeneration and vacuolization, they are usually confined to the adventitial lymphspaces, and only extend beyond this in parts near an adherent pia, or where there is intense infiltration. The same remark applies to the distribution of lymphocytes, with this difference, that these cells occur more frequently in the cells of the large vessels, and not, as do the plasma cells, in the walls of the small vessels. Most cells are spherical or ovoid in shape, with coarse basophile granules, and a large, oval, eccentrically-placed nucleus, which is badly marked off from the surrounding protoplasm; they always occur discretely. The most distinctive microscopic sign of dementia paretica is the widespread adventitial plasma cell infiltration. Plasma cells are also numerous in the general body organs. Trypanosomiasis is another chronic disease which gives considerable leucocyte and plasma cell infiltration in the perivascular spaces. Yellow pigmentary deposits may be seen in the adventitial coats of the cerebral vessels, but not quite so frequently as are seen in senile insanity. They have been taken for hematogenous matter, but may be distinguished from this substance by their paler color and waxlike appearance; occasionally, however, it may be impossible to differentiate them, as chemical tests are often unsatisfactory. The media is frequently seen to have undergone hyaline change, the muscle nuclei may scarcely show, and at times there is considerable cell infiltration. Under examination with osmic acid, the muscular tissue may show fatty degeneration; there may be a little thickening of the intima. In cases of long standing, these changes have undergone some disintegration, and partial absorption has ensued. The arteries of the pia-archnoid, as well as those of the intra-cortical tissue, are involved, and the veins are also implicated. A similar picture is present in cerebral syphilis, and in both psychoses many of the arterioles of the pia and cere- 
brum show periartritis; that is, a localized and condensed infiltration of the adventitial coats with leucocytes; proliferation of the connective tissue cells should not be mistaken for this condition. There is widespread hyaline, fibroid degeneration of the vessels of the brain, and pia-arachnoid. The capillaries of the cortex and white matter are thickened and cellular in areas. Local obliterations may cause softening and atrophy. So-called colloid degeneration of the brain extensively implicating the vessels has been carefully studied in one case reported by Alzheimer (9). According to Evenson (10), the large cerebral arteries, especially at the base, often appear rigid, gaping widely when cut across, and are dotted over with white or yellow spots; similar dottings are seen in senility. Between the endothelial layer and the elastic membrane of the intima of the larger arteries there may be observed another irregular layer made up of a fibrillary ground-work, within the meshes of which there are many cells. The elastic membrane is irregular or ragged. The muscular coat is but little affected, though fatty degeneration is at times demonstrable with osmic acid. The adventitia is thickened and often contains leucocytes and plasma cells.

The Intracranial Lymphspaces and Channels.-Strictly speaking, there are no distinct lymphatic vessels as in other parts of the body ; there are large and small spaces, and channels; the most diminutive of the latter are the intercapillary channels. The lateral ventricles are usually dilated and at times are markedly distended. Granulations of the ependymal lining are almost always present; these are considered under the neurogliar changes. After passing through the capillary walls, the lymph penetrates the small spaces of the intervascular tissue and then passes into the adventitial channels of the arterioles and venules. In many of the spaces of the pia-arachnoid and cortex, there is a round-cell invasion.

The Cerebrum.-There is considerable wasting of the brain and this is at times observable before the dura is opened; it is said (II) that on an average the brain is $15^{2}$ grams below its normal weight. This loss is much greater in cases of slow evolution. Heavy brains have been reported, but it is doubtful if these were really cases of paretica dementia. The loss in weight is not equal on the two sides, the right hemisphere usually being the 
heavier, and the difference may be as much as 50 grams. The general atrophy is most evident in the frontal and central regions. There is flattening of the convolutions, widening of the sulci, a thinning of the cortex, which latter is opaque and injected. Section of the brain shows more or less œdema and the tissue is softer than normal ; there is usually congestion and the layers are indistinct. Recent hemorrhage is often observed and atrophic areas of softening in the cortex are sometimes met with. At times there may be seen small stripes or spots which mark the line between the cortex and white matter; these are due to destruction of the fibers of Tuckek. According to Nissl, there are no gummata found in dementia paretica and in this connection Mott says it is very rare to find extensive endarteritis or gummatous syphilitic lesions in true general paralysis.

Atypical cases are sometimes met with and the disease may be ushered in by a hemianopsia; this may occur when the psychosis begins with extensive involvement of the occipital lobes. Sometimes there is an early apoplexy and focal symptoms have been known to precede the usual manifestations of dementia paretica, an occurrence which at times leads to a wrong diagnosis.

The nature of the histologic changes has been explained differently at different times. At first it was thought to be inflammatory in character; then a systemic degeneration of certain fiber tracts was considered the essential cause of the pathologic changes; at present the most common belief is that of a primary nerve element degeneration due to some toxic substance. Changes are seen in the nerve cells, nerve fibers, and in the neuroglia. The marked proliferation of blood-vessels and other vascular changes have already been considered. There is disorder and a more or less noticeable disappearance of some of the nerve cells. The cortical layers are difficult to distinguish and at times cannot be differentiated; this disarrangement of the cortical strata Nissl regards as the most noticeable and only distinctive anatomical feature of dementia paretica. The cell body is reduced in size ; it is granular and pigmented; some of the processes have disappeared and the angles are less noticeable. Changes or destruction have taken place in the Nissl bodies; the cells may be hyaline in appearance or there may be granular substance more or less diffusely distributed throughout the body of the cell. The nucleus 
is darker than normal, it is often diminished in size and sometimes appears angular; the nucleolus has also become smaller and has approached the nuclear boundary. Yellow pigmentation may be seen in many of the small cells; this never occurs normally, even in the aged.

The neuro-fibrillary changes have been studied by Schaffer (12) with the employment of Bielschowsky's silver impregnation and method; he found that all areas examined showed changes; those observed early were most noticeable in the central gyri, comparison of the cells in the paracentral lobule with those in the normal brain, showed swelling of the cell body, a diffuse staining of the apical processes and the reticulum was well preserved; often the fibrils were disintegrated and the intervening substance deeply stained. In other areas, the reticulum showed marked disintegration; sometimes there was just a disappearance of the fibrils around the nucleus. Some cells may show evidence of acute disease manifested by their being swollen and taking the stain less freely than normally; the nucleus is swollen and approximates the edge of the cell; vacuoles may appear.

As regards nerve fibers, many are destroyed; the projection fibers, as well as those concerned in association, show degeneration. The tangental fibers of the surface are usually the first to show change. The medullary tubing is at times entirely lost. Many parts of the brain are affected, but the changes are most extensive where atrophy, cellular, and vascular changes are most marked.

Trypanosome disease also shows slight nerve-cell and nervefiber destruction.

In the neuroglia there is an extensive overgrowth, especially in the superficial layers of the cortex where the fibers may penetrate the pia. The glial overgrowth is also especially marked about the cortical vessels and even in the white matter. Quite characteristic is the presence of giant cells, and a rich formation of thick fibers which are attached in bundles to the blood-vessels. The Stäbchenzelle of Nissl (13) is a long cell with a slender and an occasionally bent nucleus, the latter often being broken or shrunken; this cell may be branched and at times contains fat and pigment. Nissl believes these staff-like cells to be of neurogliar origin; they are often found near the adventitia of the capillaries and may 
have something to do with the production of these vessels. In dementia paretica they are present to a degree not found in any other disease. Granulation of the ependyma is a lesion that has received but little attention in this country; these granules are at times so thickly studded as to present the appearance of fine sand paper; they are often as large as grains of granulated sugar, and are most common in the lower half of the fourth ventricle, where they are seldom wanting. Baird (14), in 262 examinations, found them present in more than 90 per cent of the cases; they occur very early in the disease and he considers them the most characteristic naked eye sign in dementia paretica; they are not uncommon in senility and are sometimes met with in hydrocephalus; many cases of senile dementia show the condition. One explanation of their origin is that of epithelial proliferation, but their most probable derivation is that of a neurogliar overgrowth, and it seems likely that they result from irritation produced by products in the cerebrospinal fluid; these latter substances Mott (15) suggests may be due to a complex lipoid as well as a specific globulin increase, as the process of neuronic decay proceeds.

The Cranial Nerves.-In the nuclei of the cranial nerves the ganglion cells are affected by changes similar to those found in the cells of the cerebral cortex.

The optic nerve is the one most frequently affected and the changes here usually occur in the group of cases known as taboparalytics. The primary seat of the disease is probably in the retina. The atrophy is more marked towards the globe and deminishes towards the cerebrum. The retina shows degenerative changes in the ganglion cells and the nerve fibers; the vessels of the nerve show thickening and degeneration. In the nerve fibers of the optic nerve, there is breaking up of the myelin and a varicose condition of the axis-cylinders.

The vagi are frequently diseased and this has been regarded as conducive to tuberculosis of the lungs ( 16 ), a disease which quite commonly develops in dementia paretica. The ascending root of the fifth nerve is often sclerosed in the medulla. Other nerves which sometimes show changes are the olfactory, oculomotor, and hypoglossal. The cranial nuclei of the trifacial, facial, and hypoglossal nerves are frequently involved.

The Basal Ganglia.-Here are found changes similar, but less 
extensive than those observed in the cortex; there is destruction of some of the cells, a more or less loss of nerve fibers and proliferation of the neuroglia.

The Pons.-There is congestion, and areas of softening and atrophy are at times met with. The soft membranes may be adherent and they frequently contain dilated vessels.

The Cerebellum.-The changes here have been carefully studied by Sträussler (17), who states that the microscopic appearances of the disease are less pronounced than in the cerebrum. There is less meningeal thickening and the vascular changes are not so marked. Frequently, vacuolization and some loss of nerve cells are met with. The fibers are decreased; there is neurogliar proliferation and a shrinkage of the convolutions. The tissue most affected is about the semilunar sulcus, central lobe, superior lobe, inferior lobe, the nodes, and the vulva. Sometimes the cells of Purkinge are surrounded by a dense basketwork of neurogliar fibers, and the fibers of Bergman may be evident in the molecular stratum. Normally, there are no neurogliar fibers present in the granular layer, but now they may be demonstrated.

The Medulla.-Slight opacity of the surrounding membrane is sometimes met with. The nuclei of origin of the pneumogastric nerves at times show changes, and, more rarely, other nuclei do also. There is some nerve-cell disturbance and a neurogliar cell increase is observed.

The Spinal Cord.-It is pretty generally accepted that the spinal cord shows more or less change in dementia paretica. In nearly half of the cases the membranes are thickened and adherent, and there is visible shrinkage of the posterior and lateral columns. The lesions may be either diffuse or systemic. The nerve cells have undergone degeneration and atrophic changes similar to those observed in the cerebral cells. Neuro-fibrillary abnormalities have been observed here similar to those seen by Schaffer in the cells of the cerebral cortex. The microscopic changes are most frequent in the posterior ascending tracts; they are similar to, though not so extensive, as those seen in tabes. The nerve fibers show two types of lesions; (a) the tabetic type, where the degeneration is localized to the posterior columns; according to Ribaud, who examined many sections, the lesions of the posterior columns are not strictly systemic, but are character- 
ized by irregularity, which is evident from examinations of sections taken at different levels of the cord, by their diffuseness apparent in a single section of the cord, and by the frequent coexistence of spinal sclerosis with an intact condition of the roots of the zone of Lissauer; (b) combined sclerosis, where the degeneration involves both the posterior and the lateral columns.

It has been stated by Nagette, Möbius, Mott, and others, that dementia paretica and tabes are the same disease, a metasyphilitic affection in which the brunt of the disease falls in one instance upon the brain, and in the other upon the cord. In some cases both diseases seem to progress together; generally speaking, however, the psychosis has preceded the disease of the cord; these cases constitute the tabo-paralysis group.

The Cerebrospinal Fluid.-At the present time so much work is done upon this subject that additional new and important matter may be brought out at any moment. As yet, the psychiatrist is only interested in the pressure, the proteid content, and the cellular elements ; all other data is only of academic interest. The acidity or alkalinity, and the presence of a copper-reducing substance, seem so far of no practical value, although the latter substance is said by Pike (18) to be absent in dementia paretica; upon what authority this statement is made, I do not know. The fluid is always greatly increased in amount. The hydrostatic pressure, which Krönig (19) found by doing a lumbar puncture on a healthy adult person in the horizontal position to be $125 \mathrm{~mm}$., is very much raised, possibly several times above the normal. The proteid content is always increased; it is a globulin which normally does not exceed a half-gram per liter, but in dementia paretica it may be several times that amount. The globulin is of a special variety known as euglobulin and is said to carry the peculiar Wasserman anti-body. In the serum of cases of dementia paretica are usually found substances resulting from the destruction of tissue; these are lipoids and globulin and are termed anti-bodies; it is these substances upon which so much laboratory work is at present being done; this matter will only be touched upon here. The reactions and tests most studied are those of Wasserman, Noguchi, and Ross-Jones.

The Wasserman reaction, which is applicable to both blood serum and cerebrospinal fluid, was suggested basically by the 
property of hemolysis observed when the blood serum of one animal dissolves the red blood corpuscles of the blood of an animal of another species with which it is brought in contact. The reaction depends upon the presence of three substances known as compliment, which is always present in the blood serum; anti-body, which results from the reaction of the injected animal against the injected red blood cells; and antigen, which is the injected blood corpuscles. Syphilis and certain other diseases produce anti-bodies.

The technique of this reaction is sufficiently difficult to require for its application one skilled in this special kind of laboratory work. Noguchi has modified the test so that dried reagents may be used. It has been stated (20) that a positive Wasserman reaction in the blood with a positive reaction in the cerebrospinal fluid, and a lymphocytosis, points to a parasyphilitic condition of the central nervous system.

Unfortunately, it is in the early cases that the Wasserman reaction is most apt to fail, and sometimes it also fails in advanced cases, but from recent observations it seems that over 90 per cent of these patients give a positive result. The amount of so-called compliment deviation may be used as an index to the activity and duration of the disease.

The Noguchi butyric acid test depends upon the production of a flocculent precipitate when equal parts of a blood-free cerebrospinal fluid and to per cent butyric acid in normal saline solution are boiled, to which normal caustic soda solution is afterwards added, and the whole is then boiled briefly. The action is upon the globulin. A positive result is sometimes gotten in tertiary syphilis, and all forms of meningitis give the reaction.

The Ross-Jones reaction depends upon the presence of an excess of globulin, which forms a thin white film at the junction of cerebrospinal fluid with a saturated solution of ammonium sulphate. Turner (2I) states that this reaction was only positive in general paralysis and cerebral syphilis. An additional advantage is that it gives the reaction early in the disease. In 48 cases of general paralysis, or suspected general paralysis, he obtained only two negative results; one was a case of seven years' standing, and the other was a recent and doubtful case. The latest investigations seem to show that this reaction is only 
positive in dementia paretica, tabes, tertiary syphilis, and in syphilis of the nervous system.

The Cellular Elements. - Normally, only three or four cells are found to the cubic millimeter and these are exclusively endothelial cells, although the fluid after being drawn and centrifugalized may show the presence of a few erythrocytes which, however, are inconsequential. The counting is facilitated by the addition of a trace of methol violet solution, which imparts a pale tinge to the leucocytes. By cytosis is understood the presence of five or more cells per cubic millimeter; more than a hundred are at times present. The increase begins at the very onset of the disease and is more marked in the acute cases. The cytosis is especially greater as regards the polymorphonuclear leucocytes, during the seizures that occur in the disease. Most of the cells are lymphocytes, usually two-thirds are also endothelial cells, phagocytes and polymorphonuclear leucocytes. It is desirable to differentiate between endothelial cells and plasma cells. Lymphocytosis does not diminish with antisyphilitic treatment and this will distinguish it from pseudo-paralysis.

The Peripheral Nerves.-Lesions here consist in the phenomena of neuritis and atrophy analogous to those encountered in tabes and alcoholism; that is, the parenchymatous degeneration with some overgrowth of connective tissue; both motor and sensory nerves are involved.

Some Adventitious Substances.-Bodies of various sizes and shapes, whose positive chemical nature it is difficult to determine, are occasionally met with. A case of colloid degeneration of the brain extensively implicating the vessels, has been described by Alzheimer (9). Colloid bodies are at times observed in the outermost layers of the cortex and are ascribed to degeneration of the nerve fibers. They have been seen in the medulla in locomotor ataxia. (22). The writer (23) has himself studied a case of dementia paretica that had sustained repeated and severe blows to the head 20 hours before death, in which colloid bodies were found in the brain in great profusion; these bodies were not regarded as the result of the psychosis, but seemed to have resulted from rupture of the myelin sheaths with protrusion of particles of myelin; these particles responded to the tests usually applied for determining the presence of colloid bodies. 
Osteod plates are sometimes observed; they are small and may occur either as spiculæ or they may be seed-like in form; they are met with most frequently in the falx, but occasionally are seen elsewhere in the dura; they probably have little significance since they are almost as common in the sane.

Changes in Other Parts of the Body.-Unless the disease is cut short through some intercurrent affection, the patient usually dies of asthenia. In the second stage of the disease, there is usually considerable fat formation, but ultimately the emaciation is extreme ; bed-sores, which are usually present, may be of enormous extent, and they not infrequently give rise to a fatal septicamia. There may be somatic evidence of syphilis in the form of scars on the penis, thighs, and legs, and there may be nodes along the tibiæ. The cutaneous evidence of former syphilitic lesions is often wanting, and in this connection it is interesting to recall that by some, notably Fournier, it has been contended that in many cases of dementia paretica, the manifestations of the preceding syphilis have been mild in character. A neuropathic arthritis is occasionally observed in those cases attended by tabes. It differs from the common form of arthritis in being more acute, and is confined for the most part to the large joints, usually the knee. Without previous injury, the joint suddenly swells and an infusion forms which lasts for a variable time; ulceration sometimes results, new formations may develop, and displacements take place. Pain is noticeably absent. This peculiar form of arthritis has been thought to be due to changes in the anterior horns of the cord. Hematoma auris is at times present, but there is probably nothing in this condition to warrant any connection with insane states other than its development being favored in persons of lowered vitality; it occurs for the most part because of the vulnerable position of the ears, and also because of the violent tossing of the head where motor restlessness is a marked feature of a psychosis. Instances of its occurrences in normal persons are seen in injuries sustained while playing foot-ball and in other rough sports. Absorption is more common in normal persons, as in these the nutritive processes are acting more favorably, and besides better care is taken of the injured part. In the osseous system, as has been previously observed, the calvarium is thicker and denser than in the normal state, and these 
changes are distinctly different from those found in bones in other parts of the body, changes are particularly noticeable in the clavicle, femur, and ribs, and in the latter the changes at times are so marked as to permit of easy fracture between the thumb and fingers. The bones have become brittle and there has been softening and absorption in their interior; a diminution of the bone marrow is also noticeable. On microscopic examination, the bones have been described (24) as showing a granular condition of the laminæ, particularly around the Haversian canals, which latter are large, unequal, irregularly dilated, filled with opaque matter and a few oil globules. It is at times unjust to assume that fracture is the result of rough handling on the part of attendants; in addition to brittleness of the bones, these patients do not guard against danger, they are ataxic and more or less insensible to pain, and muscular action alone is at times sufficient to cause fracture.

In the vascular system marked changes are observed. There is often atrophy of the heart and valvular lesions are sometimes met with. A most common condition is that of atheroma of the aorta; in 69 cases out of 84 , Straub observed that the aorta showed signs of a syphilitic process, which he maintained was different from the atheroma of old persons. Brodington (25), from studies of the blood, found the polymorphous cells reduced in the second stage, while in the mononuclears were increased; in the third stage this was reversed. In both stages the lymphocytes were less abundant than the hyaline cells. Eosinophils were usually more numerous in the second stage, as were the mast cells, when they were found at all. Myelocytes were only occasionally seen. During convulsive seizures there was marked leucocytosis and sometimes the increase was from four to six-fold in a few hours; the increase was in the polymorphous form; hyaline cells and myelocytes were increased. The blood in the third stage was dark, viscid, and flowed with difficulty, the reds were high and the hemoglobin and specific gravity were reduced. In the third stage the blood pressure was high during excitement and low in the condition of depression.

Idelsohn (26) has observed a reduction and perhaps loss in the bacteriacidal properties of the blood. The autovirulence is increased according to D'Abundo (27). An increase of lecithin is also observed in the blood. 
The general organs of seven cases were studied by Catola (28), who found arteriosclerotic changes, capillary hyperæmia, interstitial hemorrhages, cloudy swelling, connective tissue hyperplasia, and fatty degeneration. There was a diffuse distribution of plasma cells in all organs studied, and this, the writer believes, points to dementia paretica in the absence of other special lesions to account for them.

At autopsy the lungs frequently show pneumonia and gangrene, and also tuberculosis, and this latter is said to be particularly common when the vagi are diseased.

In the urinary system there is atrophy of the kidneys in about one-third of the cases. Barnes (29), who studied the urine in five cases, summarized his observations as follows: (I) A tendency towards a low total nitrogen; (2) the undetermined rest is high and this in part is explained by the fact that all urines except one showed traces of albumin with trichloracetic acid, and that in these a few granular casts were to be made out with the microscope; (3) the neutral sulphur is in the majority of instances high, while the etherial is low. There appeared to be wide daily variations in the amounts of the urinary constituents secreted. Ball has stated that about 7 per cent of the cases show a trace of sugar. Blumenthal (30) has found an increase of lecithin in the feces. The changes in the muscles were studied some years ago by Campbell (3I), who found an extreme degree of atrophy, partial or complete disappearance of a number of muscle fibers, an increase of the nuclei of the sarcolema, and a cellular infiltration of the interstitial substance; there was a lessening in the number of the motor end-plates and some showed degeneration. He also claimed that he could demonstrate the existence of most pronounced changes in the muscular elements of the heart in cases where the vagi were diseased. This is at variance with the more recent studies of Barratt (32), who examined the vagi and sympathetic nerves from ten cases; he found no evidence of degeneration of the medullated nerves, nor was there any alteration in the connective tissue surrounding the nerve fibers; the sympathetic nerves examined were the cardiac branches of the vagi and the nerves around the coronary and splenic arteries; these showed no abnormality. This observer confirmed the previously expressed opinion of Mott "that the fatty degeneration 
of the heart and other muscular structures, which he found in general paralysis, could not be accounted for by recognizable degenerative changes in the vagus or sympathetic nerves.

In studies of body temperature, Coleburn (33) found that early cases showed no appreciable departure from the normal; late in the disease emotional excitement, epileptiform, and paralytic seizures, and minor physical disturbances produced effects upon temperature out of proportion to the causes, and elevations unaccompanied by leucocytosis occurred without assignable physical basis.

Juvenile and adolescent paresis are terms usually employed to designate cases which develop dementia paretica after having had congenital syphilis, or in persons where there has been luetic infection early in life. Although numerous cases have now been reported, it must be that the disease is often overlooked in this country, since many large institutions show no record of such cases. The disease has been observed at least as early as eight years of age, and some of the cases studied have been as old as 33. The pathologic changes seem to be identical with those found in the adult.

\section{REFERENCES}

1. Bacteriological Investigations into the Pathology of General Paralysis of the Insane. Rev. of Neurol. and Psych. April, 1903, Vol. I, p. 225. Feb., March, and April, 1906, Vol. IV.

2. Erye and Flushman: Diphtheroid Organisms in the Throats of the Insane. Arch. of Neurol. and Psych., Vol. III, p. 372.

3. Kraepelin: Psychiatrie. Johann Ambrosius Bart., Leipzig, Band II, I904, p. 353.

4. Berkley: Mental Diseases. D. Appleton \& Co., New York, 1900, p. 197.

5. Pathology of Mental Diseases. William F. Clay, Edinburgh, 1900, p. 101 .

6. A System of Syphilis. Oxford University Press, London, 1910, Vol. IV, p. 279.

7. Pathology of Mental Diseases, p. I33.

8. The Pathology of General Paralysis. Rev. of Neurol. and Psych., 1906, Vol. IV, p. 550.

9. Die Colloidentartung des Gehirns. Arch. f. Psych., I896. Band XXX, p. 16.

10. Rev. of Neurol. and Psych., 1906, Vol. IV, p. 537.

I1. Ilberg: Arch. f. Psych., I899, No. XXXI, p. 936.

12. Neurol. Centralb., I906, Vol. XXV, p. 2. 
13. Ueber einige Beziehungen zwischen Nervenzellenkrankung u. gliösen Erscheinungen bei Verscheidenen Psychosen. Arch. f. Psych., Band XXXII, H. 2.

14. The Journal of Mental Science, Jan., I910, Vol. LVI, p. 89.

15. A System of Syphilis, Vol. IV, p. 214.

16. Bianchi: La pulmonite dei paralytici e la degenerazione dei nervi vaghi. La Psychiatria, I889.

17. Jahresbericht. Psych. und Neurol., 1906, p. III9.

18. A Case of Cerebrospinal Rhinorrhoea with Double Optic Atrophy. Brit. Med. Jl., May 7, 1910, No. 2575, p. 1 ro4.

19. Deutsche med. Wochenschr. Vereins-beilage, Dec. 9, 1897, No. 52, p. 229.

20. Quoted by Harris: Syphilis in the Nervous System. Brain, June Io, Vol. XXXIII, p. 485 .

21. Examination of the Cerebrospinal Fluid as an Aid in Diagnosis in Certain Cases of Insanity, with Special Reference to the Protein Reaction as described by Ross-Jones. The J1. of Ment. Sc., July, r9ro, Vol. LVI, p. 485.

22. Woodhead: Some of the Pathological Conditions in the Medulla Oblongata, etc. In a Case of Locomotor Ataxia. Jl. Anat. and Phys., April, I882, Vol. XVI, p. 364

23. Yawger: Colloid Bodies in the Central Nervous System: Their Presence after Severe Traumatism in a Case of Dementia Paretica. Jl. of Nerv. and Ment. Dis., March, I9II.

24. Mickle: General Paralysis of the Insane; $2 d$ ed. H. K. Lewis, London, I886, p. I5I.

25. On the Condition of the Blood in General Paralysis of the Insane, with Special Reference to the Condition of the White Cells. Arch. of Neurol. and Psych., 1907, Vol. III, p. 142.

26. Ueber das Blut und dessen Bactericides Verhalten bei prog. Paralyse. Arch. f. Psych. und Nervenkrank., I899, Band XXXI, p. 640:

27. Sall' azioni bactericida e tossica del sangue negli alienati. Riv. sperim. di Freniatr., I892, Vol. XVIII, Fasc. II, p. 292.

28. Contributo allo studio dell' anatomia della paralise progressiva; alterazioni viscerale Inalche considerazione sulle plasma cellule. Riv. di Path. nerv. e ment., Jan., rgro.

29. Metabolism in General Paralysis: Urine, Blood, and Cerebrospinal Fluid. Amer. Jl. Insanity, Oct., 1909, Vol. LXVI, p. 30I.

30. Quoted by Mott: Arch. Neurol. and Psych., 1909, Vol. IV, p. 40.

31. A Contribution of the Morbid Anatomy and Pathology of the Neuromuscular Changes in General Paralysis. The Jl. of Ment. Sc., April, 1894, Vol. XL, p. 177.

32. A Research on the Condition of the Vagus and Sympathetic Nerves in General Paralysis of the Insane. Arch. of Neurol. and Psych., 1900, Vol. I, p. 332.

33. A Study of Body Temperature in General Paralysis. Amer. J1. Insanity, April, 1910, Vol. LXVI, p. 551. 